\title{
Personal carbon monoxide exposure, respiratory symptoms, and the potentially modifying roles of sex and HIV infection in rural Uganda: a cohort study
}

Crystal M. North ${ }^{1,2,3^{*}}$ (D) Piers MacNaughton², Peggy S. Lai ${ }^{1,2,3}$, Jose Vallarino ${ }^{2}$, Samson Okello $0^{2,4,5}$, Bernard Kakuhikire, ${ }^{4}$ Alexander C. Tsai ${ }^{1,3,4}$, Marcia C. Castro², Mark J. Siedner ${ }^{1,3,4}$, Joseph G. Allen ${ }^{2,3}$ and David C. Christiani ${ }^{1,2,3}$

\begin{abstract}
Background: Most of the global burden of pollution-related morbidity and mortality is believed to occur in resource-limited settings, where HIV serostatus and sex may influence the relationship between air pollution exposure and respiratory morbidity. The lack of air quality monitoring networks in these settings limits progress in measuring global disparities in pollution-related health. Personal carbon monoxide monitoring may identify subpopulations at heightened risk for air pollution-associated respiratory morbidity in regions of the world where the financial cost of air quality monitoring networks is prohibitive.

Methods: From September 2015 through May 2017, we measured 48-h ambulatory carbon monoxide (CO) exposure in a longitudinal cohort of HIV-infected and uninfected adults in rural southwestern Uganda. We fit generalized mixed effects models to identify correlates of $\mathrm{CO}$ exposure exceeding international air quality thresholds, quantify the relationship between $\mathrm{CO}$ exposure and respiratory symptoms, and explore potential effect modification by sex and HIV serostatus.

Results: Two hundred and sixty study participants completed 419 sampling periods. Personal CO exposure exceeded international thresholds for 50 (19\%) participants. In covariate-adjusted models, living in a home where charcoal was the main cooking fuel was associated with CO exposure exceeding international thresholds (adjusted odds ratio [AOR] 11.3, 95\% confidence interval [95\%Cl] 4.7-27.4). In sex-stratified models, higher CO exposure was associated with increased odds of respiratory symptoms among women (AOR 3.3, 95\%Cl 1.1-10.0) but not men (AOR 1.3, 95\% Cl 0.4-4.4). In HIV-stratified models, higher CO exposure was associated with increased odds of respiratory symptoms among HIV-infected (AOR 2.5,95\%Cl 1.01-6.0) but not HIV-uninfected (AOR 1.4, 95\%Cl 0.1-14.4) participants.

Conclusions: In a cohort in rural Uganda, personal CO exposure frequently exceeded international thresholds, correlated with biomass exposure, and was associated with respiratory symptoms among women and people living with HIV. Our results provide support for the use of ambulatory CO monitoring as a low-cost, feasible method to identify subgroups with heightened vulnerability to pollution-related respiratory morbidity in resource-limited settings and identify subgroups that may have increased susceptibility to pollution-associated respiratory morbidity.
\end{abstract}

Keywords: Africa, Biomass, Pulmonary, Air pollution, Global health

\footnotetext{
* Correspondence: cnorth@mgh.harvard.edu

${ }^{1}$ Division of Pulmonary and Critical Care Medicine, Massachusetts General

Hospital, 55 Fruit Street, BUL-148, Boston, MA 02118, USA

${ }^{2}$ Harvard T.H. Chan School of Public Health, Boston, MA, USA

Full list of author information is available at the end of the article
}

(C) The Author(s). 2019 Open Access This article is distributed under the terms of the Creative Commons Attribution 4.0 International License (http://creativecommons.org/licenses/by/4.0/), which permits unrestricted use, distribution, and reproduction in any medium, provided you give appropriate credit to the original author(s) and the source, provide a link to the Creative Commons license, and indicate if changes were made. The Creative Commons Public Domain Dedication waiver (http://creativecommons.org/publicdomain/zero/1.0/) applies to the data made available in this article, unless otherwise stated. 


\section{Background}

Air pollution, the leading environmental cause of morbidity and mortality worldwide, is responsible for over 7 million deaths annually $[1,2]$. Cooking-related biomass exposure alone causes almost 4 million deaths each year [2]. Most of the global burden of pollution-related morbidity and mortality is believed to occur in resourcelimited settings (RLS) [3], where ground-level air quality estimates are sparse due to limitations in the human capital and infrastructure necessary to establish and maintain air monitoring networks. This has limited scientific advancement in identifying vulnerable populations and quantifying the burden of pollution-related health impacts among the most affected portion of the global population.

Most of the 1 billion people with chronic respiratory disease globally live in RLS such as sub-Saharan Africa [4], where the convergence of the air pollution and HIV epidemics may underlie the disproportionate regional burden of disease. Although people living with HIV (PLWH) are more likely to have chronic lung disease due to virally-mediated lung damage and higher susceptibility to lung infections $[5,6]$, air pollution may synergistically increase lung disease risk in co-exposed populations through shared inflammatory pathways [7] and/or increased tuberculosis risk [8]. Recent data also suggest that the higher burden of air pollution-related respiratory symptoms among women in RLS - often attributed to higher exposure among women due to cooking-related biomass burning - may at least partially result from sex hormone-based differences in the pulmonary effects of inhaled pollutants [9, 10]. Despite these plausible relationships, little is known about whether these potentially vulnerable populations are at heightened risk for pollution-associated respiratory morbidity.

The scant air quality data in sub-Saharan Africa are almost exclusively from stationary samplers in urban or peri-urban centers [11], yet most of the African population lives in rural settings [12]. Furthermore, personal exposure to air pollution may not be accurately reflected by outdoor or household stationary air monitoring sites [13], which may introduce misclassification bias into studies of pollution-related health risks. Thus, while the Global Burden of Disease investigators have recently completed the first global estimates of ambient air pollution [1], estimates across sub-Saharan Africa may not reflect individual-level air pollution exposure. It is important to address this gap in knowledge because, until we have, we are ill equipped to identify and resolve global disparities in pollution-associated health effects.

Ambulatory carbon monoxide monitoring is an inexpensive, technically feasible method by which to quantify personal air pollution exposure in sub-Saharan Africa, where ground-level monitoring networks are absent. Carbon monoxide $(\mathrm{CO})$ is a byproduct of the partial combustion of carbon-containing materials, and the major sources of $\mathrm{CO}$ exposure in RLS include biomass burning and traffic-related emissions [14-17]. In some studies, ambulatory CO exposure in RLS has been shown to correlate with particulate matter concentrations [17-20]. Chronic CO exposure is associated with respiratory symptoms, lung disease exacerbations, and mortality [21-23]. To test our hypothesis, we assessed the feasibility of using ambulatory $\mathrm{CO}$ monitoring to measure personal air pollution exposure in rural southwestern Uganda, identified correlates of higher $\mathrm{CO}$ exposure, and explored whether relationships between $\mathrm{CO}$ exposure and chronic respiratory symptoms differed based on sex or HIV serostatus.

\section{Methods}

The Uganda Non-Communicable Diseases and Aging Cohort (UGANDAC) is a prospective, longitudinal observational cohort study of HIV infected and uninfected adults based in Mbarara District, Uganda [24-26]. Mbarara district, located in southwestern Uganda, includes an urban center and a larger surrounding rural area totaling $1846 \mathrm{~km}^{2}$. Most residents live in outlying rural areas, have at most a primary school education, and the local economy is dominated by petty trading, subsistence agriculture, and animal husbandry [27]. Food and water insecurity are common [28, 29]. In 2018, Uganda ranked 181st out of 192 for Gross National Income per capita, similar to most other sub-Saharan African countries [30].

The UGANDAC cohort is a mixed cohort of HIV-infected and uninfected adults. HIV-infected participants are at least 40 years of age, have been on antiretroviral therapy for at least 3 years, and receive their HIV-related care at the Mbarara Regional Referral Hospital's HIV clinic. The HIV clinic is a prototypical, PEPFAR-supported, government-run HIV clinic. Sex and age-similar (by quartile of the HIV infected sub-group) HIV-uninfected participants were selected at random from a complete population census of a village located within the clinical catchment area and confirmed to be HIV uninfected prior to each annual study visit. There were no other inclusion or exclusion criteria. We collected information on demographics, medical comorbidities, socioeconomic status (asset ownership index) [31], smoking history [32], cooking fuel use, and respiratory symptoms [33] at yearly study visits (Additional file 1). We defined self-reported respiratory symptoms as chronic cough (a cough on most days for at least 3 months), dyspnea on exertion (difficulty breathing when hurrying on a flat ground or walking up a slight hill), or wheezing (ever having a wheezy or whistling sound in the chest). All questionnaires were administered in Runyankole, 
the locally spoken dialect, by trained study staff fluent in both English and Runyakole.

From September 2015 to October 2017, we measured $48 \mathrm{~h}$ of personal exposure to carbon monoxide (CO) at annual study visits using ambulatory $\mathrm{CO}$ monitors (ELUSB-CO Data Logger, Lascar Electronics Inc., Erie, PA). Monitors are lightweight (less than one ounce, 1-in. $\times 1$ in. $\times 5$-in.), cost less than $\$ 100$ each, measure $\mathrm{CO}$ concentrations up to $1000 \mathrm{ppm}$ with an internal resolution of $0.5 \mathrm{ppm}$, and are set to $\log \mathrm{CO}$ concentrations every $60 \mathrm{~s}$ (www.dataq.com). Participants wore the $\mathrm{CO}$ monitor in a custom-made pouch at chest height for $48 \mathrm{~h}$, beginning at the completion of study procedures at each annual study visit. Participants were instructed to place the $\mathrm{CO}$ monitors at their bedside during sleep and nearby during bathing-related activities. Data were stored electronically in the monitor and uploaded to a secured, password-protected database at the completion of each sampling period. A convenience sample of software-generated graphs of $\mathrm{CO}$ concentration over time were reviewed to confirm concentration variation over the sampling period as a surrogate for study procedure compliance.

Study procedures were approved by the Mbarara University of Science and Technology and Partners Healthcare human studies ethics committees. Consistent with national guidelines, we also received clearance for the study from the Uganda National Council for Science and Technology. All participants provided written informed consent.

\section{Statistical analysis}

We first summarized cohort characteristics by HIV serostatus using Wilcoxon rank sum, chi-squared and Fisher's exact tests, as appropriate. We evaluated for selection bias by comparing cohort characteristics between those who did versus those who did not complete at least one $\mathrm{CO}$ sampling session during the study period using Wilcoxon rank sum, chi-squared or Fisher's exact tests, as appropriate.

We used the World Health Organization (WHO) air quality guidelines to define $\mathrm{CO}$ exposure thresholds. WHO guidelines stipulate that time-averaged $\mathrm{CO}$ exposure should not exceed $35 \mathrm{ppm}$ over $1 \mathrm{~h}$ (1-h timeweighted average [TWA]) or $9 \mathrm{ppm}$ over $8 \mathrm{~h}$ (8-h TWA) [34]. In studies of personal CO exposure, 1-h TWA has been shown to correlate with shorter-duration exposures while 8-h TWA has been shown to correlate with longer-duration exposures [35]. Thus, we classified participants as having $\mathrm{CO}$ exposure that exceeded WHO air quality thresholds if their highest $\mathrm{CO}$ exposure during the sampling period exceeded the 1-h TWA threshold of $35 \mathrm{ppm}$. We elected to use 1-h TWA to define exposure in our cohort because the most likely sources of $\mathrm{CO}$ in the study setting - traffic-related exposures while traveling on foot or by car and biomass exposures related to cooking, heating and lighting [36] activities - are generally shorter-term exposures. We identified the maximum 1-h TWA CO exposure in each sampling period by first calculating 1-h rolling averages across the entire 48-h sampling period and then identifying the maximum 1-h rolling average within the sampling period. To facilitate planned sensitivity analyses, we also calculated the maximum 8-h TWA CO exposure in each sampling period by first calculating 8 -h rolling averages across the entire 48-h sampling period and then identifying the maximum 8-h rolling average within the sampling period. We evaluated the correlation between maximum $1-\mathrm{h}$ and $8-\mathrm{h}$ TWA CO concentrations using the Spearman correlation coefficient.

To identify correlates of personal $\mathrm{CO}$ exposure that exceeded WHO air quality thresholds, we fitted generalized mixed effects models, with a random effect intercept to account for repeated measures of $\mathrm{CO}$ within the same participant, in the following manner. First, we identified potential correlates of interest for $\mathrm{CO}$ exposure based on scientifically plausible relationships between the candidate covariate and the exposure of interest. These included environmental exposures such as biomass use (cooking fuel type, cooking distance from main home, home lighting type), season (dry versus rainy), home location (urban versus rural), smoking (current versus non-current), occupation, burning trash near the home, and home ventilation (number of windows in the home). We then evaluated relationships between each candidate covariate and the outcome of interest in unadjusted analyses; all covariates that had a $p$-value $<0.2$ were then included in the final multivariable regression model. Participants with less than $8 \mathrm{~h}$ of $\mathrm{CO}$ data were excluded from these analyses. We evaluated the robustness of our results in a sensitivity analysis in which we defined $\mathrm{CO}$ exposure above WHO thresholds using the 8-h TWA rather than the 1-h TWA.

To evaluate the relationship between personal $\mathrm{CO}$ exposure and respiratory symptoms, we fitted generalized mixed effects models, with a random effect intercept to account for repeated measures of $\mathrm{CO}$ within the same participant, in the same manner as described above. We defined respiratory symptoms as self-reported chronic cough, dyspnea on exertion, or wheezing. In this model, 1-h TWA CO exposure above WHO thresholds was the primary explanatory variable of interest. We identified potential correlates of interest based on the scientific plausibility of their relationship with either the outcome (respiratory symptoms) or primary explanatory variable of interest ( $\mathrm{CO}$ exposure). These included age, sex, smoking status, socioeconomic status (household asset index) [31], HIV serostatus, and season (dry versus 
rainy). We then used the same multivariable logistic regression model building technique as described above whereby we included all candidate covariates with a $p$-value $<0.2$ in the final multivariable regression model, with the exception that we forced smoking status into the final model based on established relationships between smoking and respiratory morbidity.

We then evaluated for evidence of interaction between $\mathrm{CO}$ exposure and sex because of anticipated differences in $\mathrm{CO}$ exposure concentrations [20] and for evidence of interaction between $\mathrm{CO}$ exposure and HIV serostatus because of anticipated differences in respiratory symptom burden [37-39]. Beginning with the adjusted multivariable logistic regression model established through the above-described model building approach, we first conducted formal tests of interaction whereby we added CO*sex and CO*HIV interaction terms, independently, to the final model and evaluated their statistical significance. We then stratified models by HIV serostatus and by sex, respectively, to look for differential relationships between $\mathrm{CO}$ exposure and respiratory symptoms within strata.

Finally, we evaluated the robustness of our results in sensitivity analyses whereby we defined $\mathrm{CO}$ exposure above WHO thresholds using the 8-h TWA rather than the 1-h TWA. To evaluate whether CO exposure was simply a surrogate for biomass fuel type, we conducted additional sensitivity analyses in which 1) the CO exposure variable was replaced with the biomass variable, and 2) models were restricted to only those who lived in homes where firewood was the main cooking fuel rather than charcoal (biomass use for cooking is ubiquitous in the region) [40, 41]. Data were analyzed using $R$ version 3.4.2 ( $\mathrm{R}$ Project for Statistical Computing, Vienna, Austria).

\section{Results}

A total of 419 sampling periods were completed among 260 (90\%) of the 288 UGANDAC study participants (Fig. 1). Among the 260 study participants with at least one CO sampling period, 123 (47\%) were women, 131 (50\%) were HIV-infected, most $(n=221,85 \%)$ lived in rural settings, and few $(n=41,16 \%)$ were currently smoking (Table 1). Most of the cohort were subsistence farmers $(n=177,68 \%)$ and had at most a primary school education $(n=234,90 \%)$. Among the 131 participants with HIV, 122 (94\%) had undetectable HIV viral loads, 105 (80\%) had CD4 T-cell counts of at least 350 cells/ $\mathrm{mm}^{3}$, and all had been taking antiretroviral therapy for a median of 9 years (interquartile range [IQR] 8-10). Biomass exposure was ubiquitous; 221 (85\%) participants lived in homes where firewood was the main cooking fuel and 37 (14\%) lived in homes that used mainly charcoal for cooking. The cohort was nearly evenly split

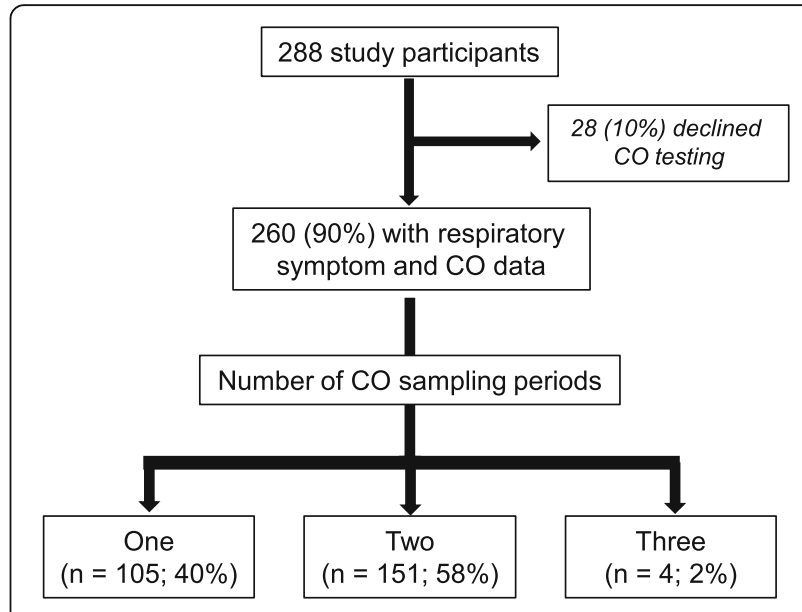

Fig. 1 Flow diagram of study participant selection

between those who used primarily kerosene to light their homes $(n=141,54 \%)$ and those who used primarily electricity, solar or battery-operated lights $(n=110,42 \%)$. The above demographics are similar to the general Ugandan population with the exception of HIV prevalence, which is $5.9 \%$ nationally [42, 43]. Trash burning at home was reported by $162(63 \%)$ of the cohort, most of whom did so less than once per week $(n=108,62 \%)$ at a median distance from home of 20 m (IQR 10 - 50). The 28 participants (10\%) who declined $\mathrm{CO}$ measurement had higher educational attainment than those who had at least one $\mathrm{CO}$ measurement $(p=0.04)$, otherwise there were no substantive differences between study participants who declined $\mathrm{CO}$ measurement as compared to those with at least one $\mathrm{CO}$ sampling period (Additional file 1: Table S1).

Among the 260 study participants who completed CO sampling periods, 105 (40\%) completed one sampling period, 151 (58\%) completed two sampling periods, and four (2\%) completed three sampling periods. Sampling periods were nearly evenly split between the dry and rainy seasons (184 [44\%] vs. 235 [56\%]). Median 24-h CO exposure was $1.5 \mathrm{ppm}$ (IQR 0.4-3.1), median 1-h time-weighted average (TWA) $\mathrm{CO}$ exposure was 8.2 ppm (IQR 3.5-18.2), and median 8-h TWA CO exposure was $2.3 \mathrm{ppm}$ (IQR 1.0-4.7). In unadjusted comparisons, ambulatory $\mathrm{CO}$ exposure was higher among participants living in homes that used charcoal for cooking as compared to firewood, among those who live in urban as compared to rural settings, among women as compared to men, and among people living with HIV (PLWH) as compared to HIV uninfected participants (Table 2, Fig. 2). Ambulatory CO levels exceeded WHO 1-h or 8-h guidelines at least once among 50 (19\%) study participants in a total of 60 (14\%) sampling periods. In multivariable-adjusted generalized 
Table 1 Cohort characteristics at baseline

\begin{tabular}{|c|c|c|c|}
\hline & $\begin{array}{l}\text { Total Cohort } \\
(n=260)\end{array}$ & $\begin{array}{l}\mathrm{HIV}+ \\
(n=131)\end{array}$ & $\begin{array}{l}\text { HIV - } \\
(n=129)\end{array}$ \\
\hline Age, years & $51[48,56]$ & $52[49,56]$ & $51[48,55]$ \\
\hline Female sex & $123(47)$ & $61(47)$ & $62(48)$ \\
\hline \multicolumn{4}{|l|}{ Smoking History } \\
\hline Never Smoker & $133(51)$ & $73(56)$ & $60(47)$ \\
\hline Former Smoker & $86(33)$ & $47(36)$ & $39(30)$ \\
\hline Current Smoker & $41(16)$ & $11(8)$ & $20(23)$ \\
\hline Years of Smoking ${ }^{a}$ & $20[10,32]$ & $16[10,25]$ & $26[11,35]$ \\
\hline Farmer & $177(68)$ & $70(53)$ & $107(83)$ \\
\hline Rural dwelling & $221(85)$ & $92(70)$ & $129(100)$ \\
\hline \multicolumn{4}{|l|}{ Education } \\
\hline Did not complete primary school & $143(55)$ & $63(48)$ & $80(62)$ \\
\hline Completed primary school & $91(35)$ & $53(40)$ & $38(29)$ \\
\hline Completed secondary school & $26(10)$ & $15(11)$ & $11(9)$ \\
\hline \multicolumn{4}{|l|}{ HIV Characteristics } \\
\hline \multicolumn{4}{|l|}{ HIV viral load, copies/ $\mu \mathrm{L}$} \\
\hline Undetectable & & $122(94)$ & \\
\hline Detectable, up to 10,000 & & $6(5)$ & \\
\hline$>10,000$ & & $2(2)$ & \\
\hline \multicolumn{4}{|l|}{ CD4 T-cell count, cells $/ \mathrm{mm}^{3}$} \\
\hline$\geq 500$ & & $54(41)$ & \\
\hline $350-499$ & & $51(39)$ & \\
\hline$<350$ & & $26(20)$ & \\
\hline Taking antiretroviral therapy & & $131(100)$ & \\
\hline Antiretroviral therapy duration, years & & $9[8,10]$ & \\
\hline \multicolumn{4}{|l|}{ Self-reported personal air quality } \\
\hline Excellent or Very good & $143(55)$ & $75(57)$ & $68(53)$ \\
\hline Fair & $69(27)$ & $36(27)$ & $33(26)$ \\
\hline Poor or Very poor & $48(18)$ & $20(15)$ & $28(22)$ \\
\hline \multicolumn{4}{|l|}{ Cooking fuel } \\
\hline Firewood & $221(85)$ & $94(73)$ & $127(98)$ \\
\hline Charcoal & $37(14)$ & $35(27)$ & $2(2)$ \\
\hline \multicolumn{4}{|l|}{ Cooking location } \\
\hline Inside the main house & $6(2)$ & $6(5)$ & $0(0)$ \\
\hline Inside a separate structure & $232(89)$ & $107(82)$ & $125(97)$ \\
\hline Outside & $22(8)$ & $18(14)$ & $4(3)$ \\
\hline Distance from house, meters ${ }^{b}$ & $1[0,5]$ & $1[0,5]$ & $4[3,5]$ \\
\hline \multicolumn{4}{|l|}{ Trash burning near home } \\
\hline None & $98(38)$ & $55(42)$ & $43(33)$ \\
\hline$<1$ times/week & $108(42)$ & $47(36)$ & $61(47)$ \\
\hline 1-6 times/week & $52(20)$ & $29(22)$ & $23(18)$ \\
\hline At least daily & $2(1)$ & $0(0)$ & $2(2)$ \\
\hline Distance from home, meters ${ }^{c}$ & $20[10,50]$ & $20[10,50]$ & $20[10,50]$ \\
\hline
\end{tabular}

Home lighting source 
Table 1 Cohort characteristics at baseline (Continued)

\begin{tabular}{|c|c|c|c|}
\hline & $\begin{array}{l}\text { Total Cohort } \\
(n=260)\end{array}$ & $\begin{array}{l}H I V+ \\
(n=131)\end{array}$ & $\begin{array}{l}\text { HIV - } \\
(n=129)\end{array}$ \\
\hline Electricity, solar power & $84(32)$ & $62(47)$ & $22(17)$ \\
\hline Kerosene & $141(54)$ & $41(31)$ & $100(78)$ \\
\hline Battery & $26(10)$ & $20(15)$ & $6(5)$ \\
\hline Candles & $6(2)$ & $5(4)$ & $1(1)$ \\
\hline \multicolumn{4}{|l|}{ Home ventilation } \\
\hline Rooms in house & $3[3,4]$ & $3[2,4]$ & $4[3,4]$ \\
\hline Windows in house & $4[3,5]$ & $4[2,4]$ & $4[4,5]$ \\
\hline Doors in house & $2[2,2]$ & $2[1,2]$ & $2[2,2]$ \\
\hline
\end{tabular}

Median [IQR], $\mathrm{n}(\%)$ unless otherwise indicated

${ }^{a}$ Current/former smokers only; ${ }^{b}$ For those who don't cook in the main house; ${ }^{c}$ For those who burn trash near their homes

mixed effects models, living in a home where charcoal as compared to firewood was the main cooking fuel was the only correlate of exposure to ambulatory $\mathrm{CO}$ concentrations exceeding WHO guidelines (adjusted odds ratio $[\mathrm{AOR}] 11.3$, 95\% confidence interval $[95 \% \mathrm{CI}] 4.7-$ 27.4, $p<0.001$ ) (Table 3). Effect estimates were similar when categorizing $\mathrm{CO}$ exposure above WHO guidelines using the 8-h rather than the 1-h TWA guideline (Additional file 1: Table S2).

Respiratory symptoms were common among the cohort. Self-reported chronic cough, dyspnea and/or wheezing were reported by 69 (27\%) study participants. In models adjusted for sex, HIV serostatus, CO exposure and smoking status, the odds of self-reported respiratory symptoms were higher among women as compared to men (AOR 4.0, 95\% CI 2.1 to
7.5, $p<0.001)$, and those with $\mathrm{CO}$ exposure over WHO guidelines had over twice the odds of any respiratory symptoms compared to those whose $\mathrm{CO}$ exposure did not exceed WHO guidelines (AOR 2.1, 95\% CI 1.0-4.7, $p=0.06$; Table 4). In models stratified by sex and HIV serostatus, $\mathrm{CO}$ exposure above WHO guidelines was associated with increased odds of respiratory symptoms among women (AOR 3.3, 95\% CI 1.1-10.0, $p=0.03$ ) but not among men and among PLWH (AOR 2.5, 95\% CI 1.01-6.0, $p=0.048$ ) but not HIV uninfected participants, although the corresponding interaction terms between $\mathrm{CO}$ exposure and either sex or HIV serostatus were not statistically significant (Tables 5 and 6). When considering each respiratory symptom individually, the relationship between higher $\mathrm{CO}$ exposure and respiratory

Table 2 Mean CO exposure concentrations [IQR] during each sampling period, $n=419$ total sampling periods

\begin{tabular}{|c|c|c|c|c|}
\hline Characteristic & 1-h TWA & $P$ value ${ }^{*}$ & 8-h TWA & $P$ value ${ }^{*}$ \\
\hline Sex & & 0.0495 & & 0.04 \\
\hline Male $(n=220)$ & $7.2[2.9,16.3]$ & & $2.1[0.7,4.4]$ & \\
\hline Female $(n=199)$ & $9.9[4.4,20.8]$ & & $2.7[1.2,5.6]$ & \\
\hline Season & & 0.32 & & 0.41 \\
\hline Dry $(n=184)$ & $7.8[3.2,14.5]$ & & $2.2[1.0,4.3]$ & \\
\hline Rainy $(n=235)$ & $8.6[3.8,19.8]$ & & $2.4[1.0,5.5]$ & \\
\hline Biomass & & $<0.0001$ & & $<0.0001$ \\
\hline Charcoal $(n=60)$ & $32.9[9.0,94.8]$ & & $9.2[2.5,28.9]$ & \\
\hline Firewood $(n=354)$ & $7.1[3.1,14.8]$ & & $2.1[0.8,4.2]$ & \\
\hline Home location & & 0.0004 & & $<0.0001$ \\
\hline Urban $(n=69)$ & $12.7[5.5,41.3]$ & & $4.4[2.2,11.6]$ & \\
\hline Rural $(n=350)$ & $7.5[3.2,16.6]$ & & $2.1[0.8,4.3]$ & \\
\hline HIV serostatus & & 0.0003 & & $<0.0001$ \\
\hline HIV infected $(n=201)$ & $10.4[4.1,27.3]$ & & $3.0[1.4,7.7]$ & \\
\hline HIV uninfected $(n=218)$ & $6.9[3.1,13.9]$ & & $1.9[0.7,3.7]$ & \\
\hline
\end{tabular}

CO Carbon monoxide, IQR Interquartile range, TWA Time-weighted average, HIV Human immunodeficiency virus *Wilcoxon rank sum tests 

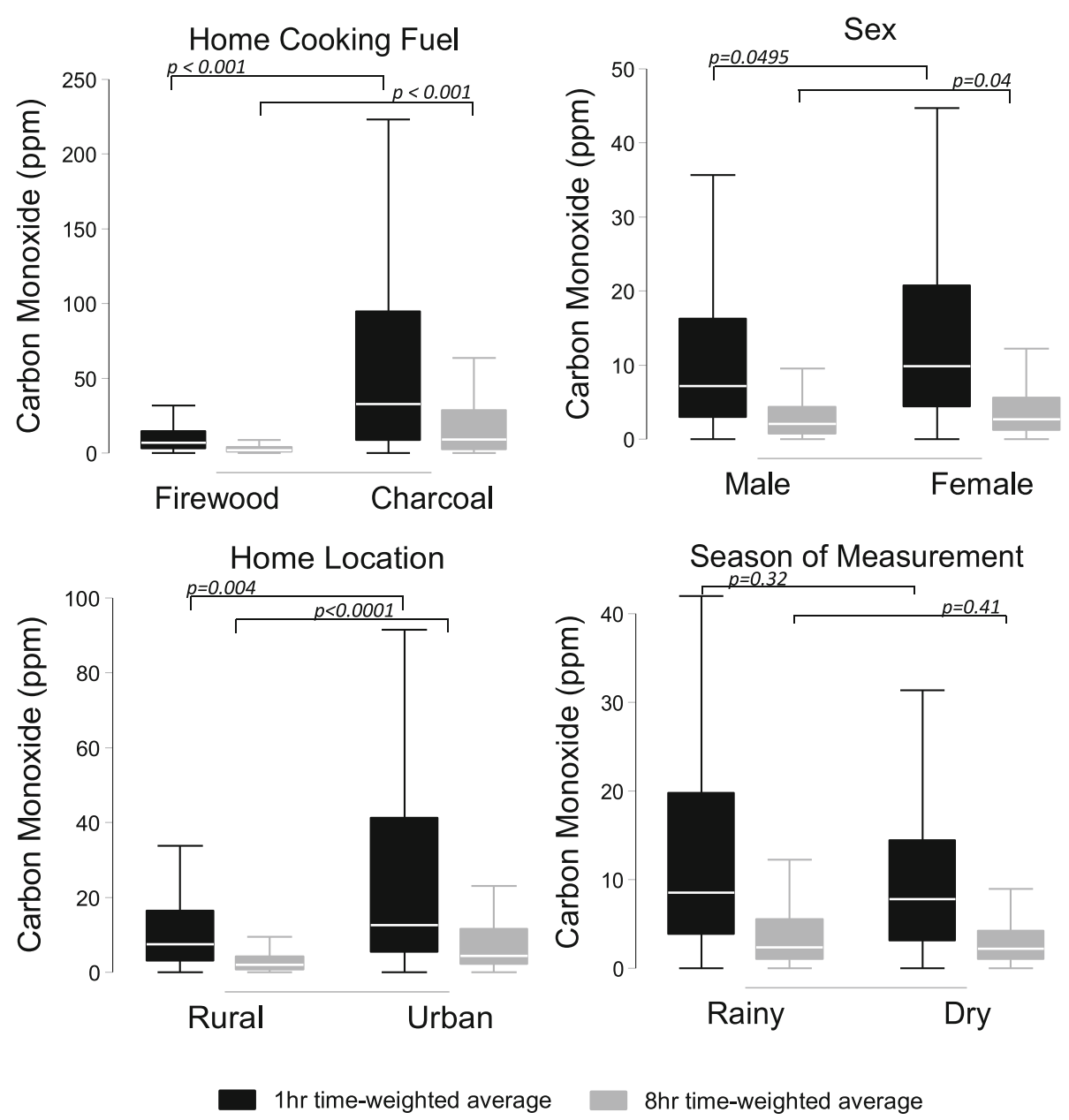

Fig. 2 Box plots represent median, 25th and 75th percentiles of carbon monoxide exposure concentrations

Table 3 Correlates of 1-h time weighted average CO exposure $>35$ ppm

\begin{tabular}{|c|c|c|c|c|}
\hline \multirow[t]{2}{*}{ Characteristic } & \multicolumn{2}{|l|}{ Unadjusted } & \multicolumn{2}{|l|}{ Adjusted } \\
\hline & Odds Ratio & $95 \% \mathrm{Cl}$ & Odds Ratio & $95 \% \mathrm{Cl}$ \\
\hline Biomass cooking - charcoal & $15.4^{* * *}$ & $7.6,31.5$ & $11.3^{* * *}$ & $4.7,27.4$ \\
\hline Kerosene lighting & $0.4^{* *}$ & $0.2,0.8$ & 0.9 & $0.4,2.0$ \\
\hline Cooking distance from home ${ }^{a}$ & 1.0 & $0.9,1.0$ & & \\
\hline Trash burning at home & 0.6 & $0.3,1.3$ & 0.5 & $0.2,1.1$ \\
\hline Dry Season & 0.8 & $0.4,1.6$ & & \\
\hline Smoking & 0.8 & $0.3,1.9$ & & \\
\hline Urban residence & $3.6^{* * *}$ & $1.8,7.4$ & 1.5 & $0.6,3.7$ \\
\hline Home ventilation $^{\mathrm{b}}$ & $0.7^{* * *}$ & $0.5,0.8$ & 0.8 & $0.7,1.0$ \\
\hline Farmer & $0.3^{* *}$ & $0.2,0.7$ & 0.9 & $0.4,2.2$ \\
\hline
\end{tabular}

Reference categories: biomass - firewood; lighting - electricity, solar, or battery power; season - rainy; residence - rural $\mathrm{CO}$ Carbon monoxide, $\mathrm{Cl}$ Confidence interval, HIV Human immunodeficiency virus

${ }^{* *} p<0.01 ;{ }^{* * *} p<0.001$

${ }^{\mathrm{a}}$ per additional meter; ${ }^{\mathrm{b}}$ per additional window 
Table 4 Correlates of self-reported respiratory symptoms

\begin{tabular}{llllll}
\hline Characteristic & \multicolumn{2}{l}{ Unadjusted } & & \multicolumn{2}{l}{ Adjusted } \\
\cline { 2 - 3 } & OR & $95 \% \mathrm{Cl}$ & & OR & $95 \% \mathrm{Cl}$ \\
\hline Age, per year & 1.0 & $0.98,1.05$ & & \\
Female sex & $2.7^{* * *}$ & $1.7,4.2$ & & $4.0^{* * *}$ & $2.1,7.5$ \\
HIV serostatus & $1.7^{*}$ & $1.1,2.7$ & & 1.1 & $0.6,2.1$ \\
1-h CO > 35 ppm & 2.0 & $0.9,4.2$ & & $2.1^{\text {a }}$ & $1.0,4.7$ \\
Dry season & 0.8 & $0.5,1.4$ & & \\
Smoking Status & & & & \\
$\quad$ Current & 0.8 & $0.4,1.7$ & 1.1 & $0.4,3.0$ \\
$\quad$ Former & 1.2 & $0.8,2.0$ & 1.1 & $0.6,2.0$ \\
Asset Index & & & & \\
$\quad$ Poorest & 1.1 & $0.6,2.0$ & & \\
$\quad$ Poorer & 0.7 & $0.4,1.3$ & & \\
Richer & 0.8 & $0.5,1.5$ & & \\
\hline
\end{tabular}

Reference categories: sex - male; HIV serostatus - HIV uninfected; season rainy; asset index - richest; smoking status - never-smoker

OR Odds ratio, $\mathrm{Cl}$ Confidence interval, $\mathrm{CO}$ Carbon monoxide, HIV Human immunodeficiency virus

${ }^{*} p<0.05 ;{ }^{* * *} p<0.001$

${ }^{a} p=0.06$

symptoms was driven by dyspnea on exertion (AOR $3.4,95 \%$ CI $1.3-9.0, p=0.01$ ), as no relationship was present with higher $\mathrm{CO}$ exposure and either cough or wheeze.

In sensitivity analyses, effect estimates were similar when using 8-h TWA limits to define WHO thresholds (Additional file 1: Tables S3-S5). Replacing the CO exposure variable with the biomass cooking variable halved the odds of respiratory symptoms associated with home cooking fuel type (AOR decreased from 2.1 to 1.0) but had no effect on other model covariates. Restricting the sample size to only those living in homes using firewood

Table $\mathbf{5}$ Correlates of self-reported respiratory symptoms, stratified by sex

\begin{tabular}{|c|c|c|c|c|}
\hline \multirow[t]{2}{*}{ Characteristic } & \multicolumn{2}{|c|}{$\begin{array}{l}\text { Men } \\
\text { (220 sampling periods) }\end{array}$} & \multicolumn{2}{|c|}{$\begin{array}{l}\text { Women } \\
\text { (200 sampling periods) }\end{array}$} \\
\hline & Adjusted OR & $95 \% \mathrm{Cl}$ & Adjusted OR & $95 \% \mathrm{Cl}$ \\
\hline HIV serostatus & $4.7^{*}$ & $1.4,16.3$ & 0.6 & $0.3,1.2$ \\
\hline 1-h CO > 35 ppm & 1.3 & $0.4,4.4$ & $3.3^{*}$ & $1.1,10.0$ \\
\hline \multicolumn{5}{|l|}{ Smoking status } \\
\hline Current & 1.4 & $0.3,6.2$ & 2.8 & $0.4,18.2$ \\
\hline Former & 1.4 & $0.5,4.2$ & 0.9 & $0.4,1.9$ \\
\hline
\end{tabular}

Reference categories: sex - male; HIV serostatus - negative; smoking - neversmoker; biomass - firewood

$p$ value for $\mathrm{CO} \times$ sex interaction term $=0.70$

OR Odds ratio, $\mathrm{Cl}$ Confidence interval, HIV Human immunodeficiency virus, $C O$

Carbon monoxide, $p p m$ Parts per million

" $p<0.05$
Table 6 Correlates of self-reported respiratory symptoms, stratified by HIV serostatus

\begin{tabular}{|c|c|c|c|c|}
\hline \multirow[t]{2}{*}{ Characteristic } & \multicolumn{2}{|c|}{$\begin{array}{l}\text { HIV Positive } \\
\text { (202 sampling periods) }\end{array}$} & \multicolumn{2}{|c|}{$\begin{array}{l}\text { HIV Negative } \\
\text { (218 sampling periods) }\end{array}$} \\
\hline & Adjusted OR & $95 \% \mathrm{Cl}$ & Adjusted OR & $95 \% \mathrm{Cl}$ \\
\hline Female sex & 1.9 & $0.8,4.3$ & $11.2^{* * *}$ & $3.3,38.0$ \\
\hline 1-h $\mathrm{CO}>35 \mathrm{ppm}$ & $2.5^{*}$ & $1.0,6.0$ & 1.4 & $0.1,14.4$ \\
\hline \multicolumn{5}{|l|}{ Smoking status } \\
\hline Current & 2.6 & $0.6,11.3$ & 0.9 & $0.1,5.0$ \\
\hline Former & 0.8 & $0.3,2.0$ & 1.3 & $0.6,3.2$ \\
\hline \multicolumn{5}{|c|}{$\begin{array}{l}\text { Reference categories: sex - male; HIV serostatus - negative; smoking - never- } \\
\text { smoker; biomass - firewood } \\
p \text { value for CO } x \text { HIV interaction term }=0.42 \\
\text { OR Odds ratio, } C \text { C Confidence interval, HIV Human immunodeficiency virus, } C O \\
\text { Carbon monoxide, } p p m \text { Parts per million } \\
{ }^{*} p<0.05 \\
{ }^{* * *} p<0.001\end{array}$} \\
\hline
\end{tabular}

for cooking had no effect on model effect estimates (Additional file 1: Tables S6 and S7).

\section{Discussion}

In a mixed cohort of people with and without HIV in rural southwestern Uganda, we found that personal $\mathrm{CO}$ exposure exceeded WHO air quality thresholds for one in five participants, that the odds of $\mathrm{CO}$ exposure exceeding air quality thresholds were over 10 times higher among those living in homes where charcoal was used for cooking, and that $\mathrm{CO}$ exposure was associated with respiratory symptoms among vulnerable populations such as women and those living with HIV.

Our study is among the first to compare personal CO exposure to $\mathrm{WHO}$ air quality thresholds in southwestern Uganda and joins few other studies of ambulatory $\mathrm{CO}$ monitoring among mixed gender populations in sub-Saharan Africa. The only other study of ambulatory $\mathrm{CO}$ levels in Uganda, in which $\mathrm{CO}$ exposure concentrations were compared by sex and age strata, similarly found that $\mathrm{CO}$ exposure was higher in women as compared to men [20]. Our results are also consistent with work from rural Malawi, where median $\mathrm{CO}$ exposure was similar and the odds of respiratory symptoms were likewise higher among those with higher CO exposure [44]. On the other hand, ambulatory $\mathrm{CO}$ levels among a cohort in urban Burkina Faso were about twice as high as those measured in our study [13], which may be related to the largely rural location of the participants in our cohort, though investigators identified a similar relationship between ambulatory $\mathrm{CO}$ levels and biomass smoke exposure. Ambulatory $\mathrm{CO}$ exposure was slightly higher among a rural Kenyan cohort of predominantly women who cooked mostly with firewood [45], which is likely due to the largely female composition of the Kenyan cohort, as meal preparation in East Africa is almost exclusively a woman's responsibility. Lastly, while 
investigators from the AIR study in urban Malawi also measured personal CO levels in a case-control study of hospitalized patients with pneumonia [46], summative $\mathrm{CO}$ levels were not presented and authors did not investigate correlates of $\mathrm{CO}$ exposure, which limits comparisons with our work.

Although the relationship that we identified between biomass use and $\mathrm{CO}$ exposure is not novel in sub-Saharan Africa [47-49], our work contributes to the literature in that we estimated personal rather than household or ambient levels. In similar settings, personal and household air quality have been found to correlate poorly [13], so assigning pollution-related health risks based on household pollutant concentrations may introduce exposure misclassification bias. Furthermore, personal $\mathrm{CO}$ exposure has been shown to correlate with personal particulate matter exposure in some [20], though not all [50-52], African populations. Thus, our use of personal $\mathrm{CO}$ concentrations may minimize exposure misclassification and provides proof-of-concept that that ambulatory $\mathrm{CO}$ measurement could be an effective method by which to identify vulnerable subgroups exposed to high levels of air pollution in a rural, RLS where biomass is the leading source of pollution [53].

This is among the first studies to suggest that the relationship between air pollution and respiratory symptoms may differ by HIV serostatus. Higher CO exposure was associated with increased odds of respiratory symptoms among PLWH but not HIV-uninfected study participants in stratified models. This finding is unlikely to be related solely to demographic-related differences in $\mathrm{CO}$ exposure because although PLWH were more likely to self-report home charcoal use and live in urban areas (both of which would increase personal $\mathrm{CO}$ exposure), they were also less likely to use biomass-based home lighting fuels or be current smokers (both of which would decrease personal CO exposure). Several potential hypotheses may explain this finding. HIV has been associated with increased respiratory morbidity in U.S. [54], European [55] and African [56, 57] cohorts. Those with HIV are thought to experience a higher burden of chronic respiratory symptoms due to a combination of higher susceptibility to lower respiratory tract infections that may cause post-infectious structural lung abnormalities $[5,58,59]$ as well as increased risk of chronic lung disease through virally-mediated effects such as accelerated immune senescence, systemic inflammation and direct pulmonary toxicity $[6,60,61]$. Based upon similarities in their relationships with systemic inflammation $[7,60]$ and lung disease [57, 62-64], chronic HIV infection and air pollution may act synergistically to worsen respiratory morbidity among co-exposed populations. Indeed, we previously found that systemic inflammation varied according to both biomass use and HIV serostatus in this cohort, and that higher indices of systemic inflammation were associated with worse lung function among both PLWH and HIV-uninfected controls [65]. Alternatively, air pollution exposure may increase the risk of pulmonary tuberculosis through smoke-induced endothelial and alveolar damage that facilitates mycobacterial infection $[8,66]$ and/or altered antimycobacterial innate immunity [67]. Thus, air pollution exposure may potentiate baseline tuberculosis risk among PLWH [68], which may underlie the increased respiratory symptom burden among PLWH as compared to HIV-uninfected participants exposed to air pollution. We did not test for tuberculosis in the cohort, so we could not evaluate the potentially mediating effect of pulmonary tuberculosis on the relationship between $\mathrm{CO}$ exposure and respiratory symptoms. If corroborated, the results of our work suggest that the convergence of the HIV and air pollution epidemics on the African continent may underlie the disproportionate regional burden of respiratory diseases.

Our work also furthers the understanding of sexbased respiratory symptom burden in sub-Saharan Africa. Respiratory symptoms are thought to be more prevalent among women in RLS because women are generally responsible for meal preparation and thus exposed to more indoor air pollution. The results of this work may challenge that assumption because the relationship between female sex and respiratory symptoms persisted even after adjusting for personal $\mathrm{CO}$ exposure. One potential mechanism that may explain this finding is sex-based differences in susceptibility to the respiratory effects of inhaled pollutants. Tobacco smoke, for example, has a greater impact on lung function among women as compared to men $[9,69]$, possibly related to sex hormone-based effect potentiation [70, 71]. In a cohort study of 39 healthy young adults, short-term wood smoke particle exposure also differentially impacted influenza virus-associated changes in nasal inflammatory gene expression profiles in a sexdependent manner [10]. Among those exposed to wood smoke particles before inoculation, virus-associated gene expression was increased among men but decreased among women, which suggests that inhaled pollutants also impact respiratory virus susceptibility differentially based on sex. Consistent with these sexbased differences, we found that at similar levels of exposure, CO-exposed women had increased odds of respiratory symptoms as compared to CO-exposed men, and our group has previously shown that systemic inflammation is higher among women as compared to men in this cohort [26]. Our findings suggest that sexbased differences in biomass exposure levels may only partially explain the association between female sex and respiratory morbidity in RLS. 
The main strength of our analysis is the use of a wellcharacterized, population-based cohort in rural Uganda with repeated measures of air quality. Our use of ambulatory monitors also makes our results less susceptible to exposure misclassification bias compared to area monitors. Our study also has several limitations. Firstly, our study participants did not complete time-activity analyses, so we could not correlate peaks of $\mathrm{CO}$ exposure with specific activities, which may have limited our identification of additional predictors of $\mathrm{CO}$ exposure. Additionally, we did not formally monitor device use compliance, so some participants may not have worn the devices for the entire sampling period. However, we have no reason to believe that non-use would be nonrandom, so would suggest that the exposure misclassification bias this may have introduced would be most expected to bias our results towards the null, further underscoring the significance of our findings. Secondly, while repeated $\mathrm{CO}$ measurement periods are more likely to approximate chronic exposure compared with single measurements, they may still not be fully reflective of chronic exposures and thus may misclassify exposure. We also use ambulatory $\mathrm{CO}$ measures to estimate personal air quality, which is supported by the work of some $[17,18]$ but not all [50-52] groups who have evaluated the correlation between personal $\mathrm{CO}$ and particulate matter exposure in similar settings. Additionally, sputum samples were not available for analysis, so we were unable to evaluate participants for active tuberculosis. However, the degree of viral control and the TB incidence in Uganda make undiagnosed active tuberculosis less likely [72, 73]. Though we identified differences in the relationship between $\mathrm{CO}$ exposure and respiratory symptoms in analyses stratified by sex and HIV serostatus, the associated tests for interaction were not statistically significant, so further work is necessary to explore whether sex or HIV serostatus modify the relationship between air pollution and respiratory morbidity. Lastly, while our results are generalizable to adults living in rural Uganda, future studies are needed to evaluate the generalizability of these findings to other priority populations in sub-Saharan Africa, including children.

\section{Conclusions}

In summary, our data offer proof-of-concept that ambulatory $\mathrm{CO}$ monitoring is a low-cost and feasible means of assessing personal air quality in a rural sub-Saharan African region, identify biomass smoke as an important source of ambulatory $\mathrm{CO}$ exposure, and explore potential differences in pollution-associated respiratory morbidity based on HIV serostatus and sex. These findings are important because they extend our knowledge of which populations are most susceptible to pollutionrelated respiratory morbidity in resource-limited settings, which is critical to informing policy interventions focused on decreasing respiratory morbidity among the most vulnerable populations. Future work is needed to formally evaluate the potentially interactive relationships between air pollution and both sex and HIV serostatus. If corroborated, the results of our work suggest that the convergence of the HIV and air pollution epidemics may underlie the disproportionate regional burden of respiratory morbidity on the African continent and may highlight vulnerable populations on which future exposure mitigation efforts must focus.

\section{Additional file}

\begin{abstract}
Additional file 1: Figure S1. Study Questionnaire. Table S1. Cohort Characteristics at baseline comparing participants who completed at least one CO measurement to participants who declined CO measurements. Table S2. Correlates of 8 -h time weighted average CO exposure $>9$ ppm. Table S3. Correlates of self-reported respiratory symptoms. Table S4. Correlates of self-reported respiratory symptoms, stratified by sex. Table S5. Correlates of self-reported respiratory symptoms, stratified by HIV serostatus. Table S6. Correlates of self-reported respiratory symptoms, sensitivity analysis replacing the CO exposure variable with the biomass cooking variable $(n=415)$. Table S7. Correlates of selfreported respiratory symptoms, sensitivity analysis removing those living in homes where charcoal is used for cooking $(n=355)$. (DOCX $54 \mathrm{~kb}$ )
\end{abstract}

\section{Abbreviations}

AOR: Adjusted odds ratio; Cl: Confidence interval; CO: Carbon monoxide; HIV: Human immunodeficiency virus; IQR: Interquartile range; PLWH: People living with HIV; ppm: Parts per million; RLS: Resource-limited settings; TWA: Time-weighted average; WHO: World health organization

\section{Acknowledgements}

We would like to thank the study participants of the Uganda NonCommunicable Diseases and Aging Cohort, who made this study possible. We would also like to thank Ruth Sentongo, Alan Babweteera, Zulaika Namboga, Sheila Abaasabyoona and Doreen Kyomuhendo for their research assistance. No endorsement of manuscript contents or conclusions should be inferred from these acknowledgements.

\section{Authors' contributions}

CMN and DCC conceived of the study design. JV, MC, PSL, JGA and DCC provided methodological guidance. CMN, OS, BK, ACT and MJS oversaw data collection. CMN and PM completed all statistical analyses. CMN wrote the first draft of the manuscript, all co-authors provided critical input in manuscript preparation, and all co-authors approved the final manuscript.

\section{Funding}

The results reported herein correspond to specific aims of $\mathrm{NIH}$ grant awards R25TW009337 (CMN), P30ES000002 (CMN), and R21HL124712 (MJS). This work was also supported by NIH grant awards P30AI060354, R24AG044325, R01MH113494, T32HL116275, K23MH099916, K43TW010715, and K23ES023700. Biostatistical consultation was provided with support from Harvard Catalyst | The Harvard Clinical and Translational Science Center (National Center for Research Resources and the National Center for Advancing Translational Sciences, National Institutes of Health Award UL1TR001102) and financial contributions from Harvard University and its affiliated academic healthcare centers. The content is solely the responsibility of the authors and does not necessarily represent the official views of the Harvard Catalyst, Harvard University and its affiliated academic healthcare centers, or the National Institutes of Health. The funding bodies named above had no role in the design of the study, in the collection, analysis or interpretation of the data, or in the writing of the manuscript. 


\section{Availability of data and materials}

The datasets used and/or analyzed during the current study are available from the corresponding author on reasonable request.

\section{Ethics approval and consent to participate}

Study procedures were approved by the Mbarara University of Science and Technology (Uganda) and Partners Healthcare (Boston, MA) human studies ethics committees. Consistent with national guidelines, we also received clearance for the study from the Uganda National Council for Science and Technology. All participants provided written informed consent.

\section{Consent for publication}

Not applicable

\section{Competing interests}

The authors declare that they have no competing interests.

\section{Author details}

'Division of Pulmonary and Critical Care Medicine, Massachusetts General Hospital, 55 Fruit Street, BUL-148, Boston, MA 02118, USA. ${ }^{2}$ Harvard T.H. Chan School of Public Health, Boston, MA, USA. ${ }^{3}$ Harvard Medical School, Boston, MA, USA. ${ }^{4}$ Mbarara University of Science and Technology, Mbarara, Uganda. ${ }^{5}$ University of Virginia Health System, Charlottesville, USA.

Received: 19 January 2019 Accepted: 12 August 2019

Published online: 20 August 2019

\section{References}

1. Cohen AJ, Brauer M, Burnett R, Anderson HR, Frostad J, Estep K, Balakrishnan K, Brunekreef B, Dandona L, Dandona R, et al. Estimates and 25-year trends of the global burden of disease attributable to ambient air pollution: an analysis of data from the global burden of diseases study 2015. Lancet. 2017:389:1907-18

2. World Health Organization. Mortality from household and ambient air pollution. Global Health Observatory data. [http://www.who.int/gho/phe/ air_pollution_mortality/en/]. Accessed 13 Dec 2018.

3. World Health Organization. Burden of Disease from Ambient Air Pollution for 2016 [http://www.who.int/airpollution/data/AAP_BoD_results_May2018_ final.pdf]. Accessed 13 Dec 2018.

4. World Health Organization. Global status report on non-communicable diseases 2014. Geneva: WHO. p. 2014

5. Low A, Gavriilidis G, Larke N, MR BL, Drouin O, Stover J, Muhe L, Easterbrook $P$. Incidence of opportunistic infections and the impact of antiretroviral therapy among HIV-infected adults in low- and middle-income countries: a systematic review and meta-analysis. Clin Infect Dis. 2016;62:1595-603.

6. Brune KA, Ferreira F, Mandke P, Chau E, Aggarwal NR, D'Alessio FR, Lambert AA, Kirk G, Blankson J, Drummond MB, et al. HIV impairs lung epithelial integrity and enters the epithelium to promote chronic lung inflammation. PLoS One. 2016;11:e0149679.

7. Roy A, Gong J, Thomas DC, Zhang J, Kipen HM, Rich DQ, Zhu T, Huang W, Hu M, Wang G, et al. The cardiopulmonary effects of ambient air pollution and mechanistic pathways: a comparative hierarchical pathway analysis. PLoS One. 2014:9:e114913.

8. Sumpter C, Chandramohan D. Systematic review and meta-analysis of the associations between indoor air pollution and tuberculosis. Tropical Med Int Health. 2013;18:101-8.

9. Amaral AFS, Strachan DP, Burney PGJ, Jarvis DL. Female smokers are at greater risk of aiflow obstruction than male smokers. UK Biobank. Am J Respir Crit Care Med. 2017;195:1226-35.

10. Rebuli ME, Speen AM, Martin EM, Addo KA, Pawlak EA, Glista-Baker E, Robinette C, Zhou H, Noah TL, Jaspers I. Wood smoke exposure alters human inflammatory responses to viral infection in a sex-specific manner. A randomized, placebo-controlled study. Am J Respir Crit Care Med. 2019:199:996-1007.

11. Ambient Air Quality Database. World Health Organization; 2018

12. World Bank Open Data. The World Bank Group, 2017. [https://data.worldbank.org/]

13. Yamamoto SS, Louis VR, Sie A, Sauerborn R. Biomass smoke in Burkina Faso: what is the relationship between particulate matter, carbon monoxide, and kitchen characteristics? Environ Sci Pollut Res Int. 2014;21:2581-91.
14. Hao J, Wu Y, Fu L, He D, He K. Source contributions to ambient concentrations of $\mathrm{CO}$ and $\mathrm{NOx}$ in the urban area of Beijing. J Environ SCi Health A. 2001;36:215-28.

15. Guo H, Wang T, Simpson I, Blake D, Yu X, Kwok Y, Li Y. Source contributions to ambient VOCs and $\mathrm{CO}$ at a rural site in eastern China. Atmos Environ. 2004:38:4551-60.

16. Wallington TJ, Sullivan JL, Hurley MD. Emissions of $\mathrm{CO} 2, \mathrm{CO}, \mathrm{NOx}, \mathrm{HC}, \mathrm{PM}$, $\mathrm{HFC}-134 \mathrm{a}, \mathrm{N} 2 \mathrm{O}$ and $\mathrm{CH} 4$ from the global light duty vehicle fleet. Meteorol Z. 2008;17:109-16.

17. McCracken JP, Schwartz J, Diaz A, Bruce N, Smith KR. Longitudinal relationship between personal $\mathrm{CO}$ and personal PM2. 5 among women cooking with woodfired cookstoves in Guatemala. PLoS One. 2013;8:e55670.

18. Northcross A, Chowdhury Z, McCracken J, Canuz E, Smith KR. Estimating personal PM2.5 exposures using CO measurements in Guatemalan households cooking with wood fuel. J Environ Monit. 2010;12:873-8.

19. Naeher LP, Smith KR, Leaderer BP, Neufeld L, Mage DT. Carbon monoxide as a tracer for assessing exposures to particulate matter in wood and gas cookstove households of highland Guatemala. Environ Sci Technol. 2001:35:575-81.

20. Okello G, Devereux G, Semple S. Women and girls in resource poor countries experience much greater exposure to household air pollutants than men: results from Uganda and Ethiopia. Environ Int. 2018;119:429-37.

21. Moore E, Chatzidiakou L, Kuku MO, Jones RL, Smeeth L, Beevers S, Kelly FJ, Barratt B, Quint JK. Global associations between air pollutants and chronic obstructive pulmonary disease hospitalizations. A systematic review. Ann Am Thorac Soc. 2016:13:1814-27.

22. Burnett RT, Cakmak S, Raizenne ME, Stieb D, Vincent R, Krewski D, Brook JR, Philips O, Ozkaynak $\mathrm{H}$. The association between ambient carbon monoxide levels and daily mortality in Toronto, Canada. J Air Waste Manage Assoc. 1998:48:689-700.

23. Pope D, Diaz E, Smith-Sivertsen T, Lie RT, Bakke P, Balmes JR, Smith KR, Bruce NG. Exposure to household air pollution from wood combustion and association with respiratory symptoms and lung function in nonsmoking women: results from the RESPIRE trial, Guatemala. Environ Health Perspect. 2015;123:285-92.

24. Feinstein MJ, Kim JH, Bibangambah P, Sentongo R, Martin JN, Tsai AC, Bangsberg DR, Hemphill L, Triant VA, Boum Y 2nd, et al. Ideal cardiovascular health and carotid atherosclerosis in a mixed cohort of HIV-infected and uninfected Ugandans. AIDS Res Hum Retrovir. 2017;33:49-56.

25. Siedner MJ, Kim JH, Nakku RS, Hemphill L, Triant VA, Haberer JE, Martin JN, Boum Y 2nd, Kwon DS, Tsai AC, et al. HIV infection and arterial stiffness among older-adults taking antiretroviral therapy in rural Uganda. AIDS. 2016;30:667-70.

26. Siedner MJ, Zanni M, Tracy RP, Kwon DS, Tsai AC, Kakuhire B, Hunt PW, Okello S. Increased systemic inflammation and gut permeability among women with treated HIV infection in rural Uganda. J Infect Dis. 2018;218:922-6.

27. Uganda Bureau of Statistics 2016, The National Population and Housing Census 2014 - Main Report, Kampala, Uganda. https://unstats.un.org/unsd/ demographic/sources/census/wphc/Uganda/UGA-2016-05-23.pdf.

28. Tsai AC, Kakuhikire B, Mushavi R, Vorechovska D, Perkins JM, McDonough AQ, Bangsberg DR. Population-based study of intra-household gender differences in water insecurity: reliability and validity of a survey instrument for use in rural Uganda. J Water Health. 2016:14:280-92.

29. Tsai AC, Bangsberg DR, Frongillo EA, Hunt PW, Muzoora C, Martin JN, Weiser SD. Food insecurity, depression and the modifying role of social support among people living with HIV/AIDS in rural Uganda. Soc Sci Med. 2012;74:2012-9.

30. Gross National Income per Capita 2018. Atlas method and PPP: World Bank Group; 2019. https://datacatalog.worldbank.org/dataset/gni-capita-rankingatlas-method-and-ppp-based.

31. Filmer D, Pritchett LH. Estimating wealth effects without expenditure data_or tears: an application to educational enrollments in states of India. Demography. 2001;38:115-32.

32. World Health Organization. www.who.int. The STEPS Instrument and Support Materials [http://www.who.int/chp/steps/riskfactor/en/]. Accessed 13 Dec 2018.

33. Ferris BG. Epidemiology standardization project (American Thoracic Society). Am Rev Respir Dis. 1978;118:1-120.

34. WHO. Air quality guidelines for particulate matter, ozone, nitrogen dioxide and sulfer dioxide: global update 2005: summary of risk assessment. World Health Organization, Occupational and Environmental Health Team. [http:// www.who.int/iris/handle/10665/69477]. Accessed 5 Dec 2018. 
35. Bruinen de Bruin Y, Carrer P, Jantunen M, Hanninen O, Di Marco GS, Kephalopoulos S, Cavallo D, Maroni M. Personal carbon monoxide exposure levels: contribution of local sources to exposures and microenvironment concentrations in Milan. J Expo Anal Environ Epidemiol. 2004;14:312-22.

36. Muyanja D, Allen JG, Vallarino J, Valeri L, Kakuhikire B, Bangsberg DR, Christiani DC, Tsai AC, Lai PS. Kerosene lighting contributes to household air pollution in rural Uganda. Indoor Air. 2017;27:1022-9.

37. Nliwasa M, MacPherson P, Mukaka M, Mdolo A, Mwapasa M, Kaswaswa K, Msefula C, Chipungu G, Mwandumba HC, Corbett EL. High mortality and prevalence of HIV and tuberculosis in adults with chronic cough in Malawi: a cohort study. Int J Tuberc Lung Dis. 2016;20:202-10.

38. Munyati SS, Dhoba T, Makanza ED, Mungofa S, Wellington M, Mutsvangwa J, Gwanzura L, Hakim J, Nyakabau M, Mason PR, et al. Chronic cough in primary health care attendees, Harare, Zimbabwe: diagnosis and impact of HIV infection. Clin Infect Dis. 2005;40:1818-27.

39. Meghii J, Nadeau G, Davis KJ, Wang D, Nyirenda MJ, Gordon SB, Mortimer K. Noncommunicable lung disease in sub-Saharan Africa. A community-based cross-sectional study of adults in urban Malawi. Am J Respir Crit Care Med. 2016:194:67-76

40. North CM, Valeri L, Hunt PW, Mocello AR, Martin JN, Boum Y 2nd, Haberer JE, Bangsberg DR, Christiani DC, Siedner MJ. Cooking fuel and respiratory symptoms among people living with HIV in rural Uganda. ERJ Open Res. 2017;3. https://doi.org/10.1183/23120541.00094-2016.

41. North CM, Allen JG, Okello S, Sentongo R, Kakuhikire B, Ryan ET, Tsai AC, Christiani DC, Siedner MJ. HIV infection, pulmonary tuberculosis, and COPD in rural Uganda: a cross-sectional study. Lung. 2018;196:49-57.

42. Uganda Bureau of Statistics (UBOS) and ICF. Uganda demographic and health survey 2016. Kampala and Rockville: UBOS and ICF; 2018. [www.ubos.org]

43. UNAIDS. Country factsheets: Uganda. 2017 [http://www.unaids.org/en/ regionscountries/countries/uganda].

44. Nightingale R, Lesosky M, Flitz G, Rylance SJ, Meghji J, Burney P, Balmes J, Mortimer K. Noncommunicable respiratory disease and air pollution exposure in Malawi (CAPS). A cross-sectional study. Am J Respir Crit Care Med. 2019;199:613-21.

45. Lam NL, Muhwezi G, Isabirye F, Harrison K, Ruiz-Mercado I, Amukoye E, Mokaya T, Wambua M, Bates MN. Exposure reductions associated with introduction of solar lamps to kerosene lamp-using households in Busia County, Kenya. Indoor Air. 2018;28:218-27.

46. Jary HR, Aston S, Ho A, Giorgi E, Kalata N, Nyirenda M, Mallewa J, Peterson I, Gordon SB, Mortimer K. Household air pollution, chronic respiratory disease and pneumonia in Malawian adults: a case-control study. Wellcome Open Res. 2017:2:103.

47. Thorsson S, Holmer B, Andjelic A, Lindén J, Cimerman S, Barregard L. Carbon monoxide concentrations in outdoor wood-fired kitchens in Ouagadougou, Burkina Faso_-implications for women's and children's health. Environ Monit Assess. 2014;186:4479-92.

48. Viau C, Hakizimana G, Bouchard M. Indoor exposure to polycyclic aromatic hydrocarbons and carbon monoxide in traditional houses in Burundi. Int Arch Occup Environ Health. 2000;73:331-8.

49. Wylie BJ, Kishashu Y, Matechi E, Zhou Z, Coull B, Abioye Al, Dionisio KL, Mugusi F, Premji Z, Fawzi W, et al. Maternal exposure to carbon monoxide and fine particulate matter during pregnancy in an urban Tanzanian cohort. Indoor Air. 2017;27:136-46.

50. Wylie BJ, Matechi E, Kishashu Y, Fawzi W, Premji Z, Coull BA, Hauser R, Ezzati M, Roberts DJ. Placental pathology associated with household air pollution in a cohort of pregnant women from Dar es Salaam, Tanzania. Environ Health Perspect. 2017;125:134-40.

51. Carter E, Norris C, Dionisio KL, Balakrishnan K, Checkley W, Clark ML, Ghosh S, Jack DW, Kinney PL, Marshall JD, et al. Assessing exposure to household air pollution: a systematic review and pooled analysis of carbon monoxide as a surrogate measure of particulate matter. Environ Health Perspect. 2017;125:076002.

52. Klasen EM, Wills B, Naithani N, Gilman RH, Tielsch JM, Chiang M, Khatry S, Breysse PN, Menya D, Apaka C, et al. Low correlation between household carbon monoxide and particulate matter concentrations from biomass-related pollution in three resource-poor settings. Environ Res. 2015;142:424-31.

53. Karagulian F, Belis CA, Dora CFC, Prüss-Ustün AM, Bonjour S, Adair-Rohani $H$, Amann M. Contributions to cities' ambient particulate matter (PM): a systematic review of local source contributions at global level. Atmos Environ. 2015;120:475-83.

54. Crothers K, Huang L, Goulet JL, Goetz MB, Brown ST, Rodriguez-Barradas MC, Oursler KK, Rimland D, Gibert CL, Butt AA, Justice AC. HIV infection and risk for incident pulmonary diseases in the combination antiretroviral therapy era. Am J Respir Crit Care Med. 2011;183:388-95.

55. Makinson A, Hayot M, Eymard-Duvernay S, Ribet C, Raffi F, Pialoux G, Zucman D, Poizot-Martin I, Bonnet F, Abgrall S, et al. HIV is associated with airway obstruction: a matched controlled study. AIDS. 2018;32:227-32.

56. Pefura-Yone EW, Fodjeu G, Kengne AP, Roche N, Kuaban C. Prevalence and determinants of chronic obstructive pulmonary disease in HIV infected patients in an African country with low level of tobacco smoking. Respir Med. 2015;109:247-54.

57. Akanbi MO, Taiwo BO, Achenbach CJ, Ozoh OB, Obaseki DO, Sule H, Agbaji OO, Ukoli CO. HIV associated chronic obstructive pulmonary disease in Nigeria. J AIDS Clin Res. 2015;6(5):453

58. Lowe DM, Rangaka MX, Gordon F, James CD, Miller RF. Pneumocystis jirovecii pneumonia in tropical and low and middle income countries: a systematic review and meta-regression. PLoS One. 2013;8:e69969.

59. Allwood BW, Myer L, Bateman ED. A systematic review of the association between pulmonary tuberculosis and the development of chronic airflow obstruction in adults. Respiration. 2013;86:76-85.

60. Fitzpatrick ME, Singh V, Bertolet M, Lucht L, Kessinger C, Michel J, Logar A, Weinman R, McMahon D, Norris KA, et al. Relationships of pulmonary function, inflammation, and T-cell activation and senescence in an HIVinfected cohort. AIDS. 2014;28:2505-15.

61. Neuhaus J, Jacobs DR Jr, Baker JV, Calmy A, Duprez D, La Rosa A, Kuller LH, Pett SL, Ristola M, Ross MJ, et al. Markers of inflammation, coagulation, and renal function are elevated in adults with HIV infection. J Infect Dis. 2010;201:1788-95.

62. Crothers K, Butt AA, Gibert CL, Rodriguez-Barradas MC, Crystal S, Justice AC. Veterans aging cohort 5 project T: increased COPD among HIV-positive compared to HIV-negative veterans. Chest. 2006;130:1326-33.

63. Gingo MR, Balasubramani GK, Rice TB, Kingsley L, Kleerup EC, Detels R, Seaberg EC, Greenblatt RM, Holman S, Huang L, et al. Pulmonary symptoms and diagnoses are associated with HIV in the MACS and WIHS cohorts. BMC Pulm Med. 2014;14:75.

64. Rice MB, Ljungman PL, Wilker EH, Dorans KS, Gold DR, Schwartz J, Koutrakis P, Washko GR, O'Connor GT, Mittleman MA. Long-term exposure to traffic emissions and fine particulate matter and lung function decline in the Framingham heart study. Am J Respir Crit Care Med. 2015;191:656-64.

65. North CM, Muyanja D, Kakuhikire B, Tsai AC, Tracy RP, Hunt PW, Kwon DS, Christiani DC, Okello S, Siedner MJ. Brief report: systemic inflammation, immune activation, and impaired lung function among people living with HIV in rural Uganda. J Acquir Immune Defic Syndr. 2018;78:543-8.

66. Kurmi OP, Sadhra CS, Ayres JG, Sadhra SS. Tuberculosis risk from exposure to solid fuel smoke: a systematic review and meta-analysis. J Epidemiol Community Health. 2014;68:1112-8.

67. Rivas-Santiago CE, Sarkar S, Cantarella P, Osornio-Vargas A, QuintanaBelmares R, Meng Q, Kirn TJ, Ohman Strickland P, Chow JC, Watson JG, et al. Air pollution particulate matter alters antimycobacterial respiratory epithelium innate immunity. Infect Immun. 2015;83:2507-17.

68. Liu E, Makubi A, Drain P, Spiegelman D, Sando D, Li N, Chalamilla G, Sudfeld $C R$, Hertzmark E, Fawzi WW. Tuberculosis incidence rate and risk factors among HIV-infected adults with access to antiretroviral therapy. AIDS. 2015;29:1391-9.

69. Gan WQ, Man SF, Postma DS, Camp P, Sin DD. Female smokers beyond the perimenopausal period are at increased risk of chronic obstructive pulmonary disease: a systematic review and meta-analysis. Respir Res. 2006;7:52.

70. Hardin M, Cho MH, Sharma S, Glass K, Castaldi PJ, McDonald ML, Aschard H, Senter-Sylvia J, Tantisira K, Weiss ST, et al. Sex-based genetic association study identifies CELSR1 as a possible chronic obstructive pulmonary disease risk locus among women. Am J Respir Cell Mol Biol. 2017;56:332-41.

71. Tam A, Churg A, Wright JL, Zhou S, Kirby M, Coxson HO, Lam S, Man SF, Sin DD. Sex differences in airway remodeling in a mouse model of chronic obstructive pulmonary disease. Am J Respir Crit Care Med. 2016;193:825-34.

72. Suthar AB, Lawn SD, Del Amo J, Getahun H, Dye C, Sculier D, Sterling TR, Chaisson RE, Williams BG, Harries AD. Antiretroviral therapy for prevention of tuberculosis in adults with HIV: a systematic review and meta-analysis. PLoS Med. 2012;9:e1001270.

73. Van Rie A, Westreich D, Sanne I. Tuberculosis in patients receiving antiretroviral treatment: incidence, risk factors and prevention strategies. J Acquir Immune Defic Syndr (1999). 2011;56:349.

\section{Publisher's Note}

Springer Nature remains neutral with regard to jurisdictional claims in published maps and institutional affiliations. 